\title{
AFTERNOON SESSION
}

\section{Chairman: Dr. G. BEDBROOK}

Sir Ludwig GutTmann (Great Britain). The chairman of the afternoon session will be Dr. George Bedbrook from Perth, Western Australia. Most of you know of the great work he is doing for spinal cord sufferers in Australia. But for some years he was also engaged to spread the gospel of modern treatment of paraplegics and tetraplegics to various countries in the Far East. I visited him first in 1957 when his unit was small and only two years old. It was just the time when he became disillusioned with the result of surgery in fractures of the spine, especially open reduction and metal plate fixation. When I visited him again in 1962 on the occasion of the first British Commonwealth Paraplegic Games held in Perth, his unit had expanded to a first class Spinal Centre. Dr. Bedbrook was one of the first in Australia to realise the need of hostels for those paraplegics and, in particular, tetraplegics who for one reason or another are unable to return home. This is now a very important problem which concerns all of us who are engaged in work with these severely disabled people in view of the ever increasing number of these patients and their prolonged life expectancy. These patients just cannot be managed in geriatric units or similar institutions. They develop bedsores and other complications very soon and have to be readmitted to hospitals or spinal units for usually very long lasting inpatient treatment. To obviate this sorry state of affairs it is essential to erect hostels with sheltered workshop facilities for these patients in the neighbourhood of spinal units, with a skeleton staff to look after them and supervised by the staff of the spinal unit. In Great Britain the first of such a hostel of 30 beds has been introduced by me at Stoke Mandeville Hospital a few years ago and has proved highly successful. It is to be hoped that more hostels of this kind will be set up in the country. In Perth Dr. Bedbrook has taken the initiative in this respect and I am sure he will succeed.

Now it is a great pleasure to ask Dr. Bedbrook to take the chair.

Dr. Bedbrook (Australia). Mr. President, Ladies and Gentlemen: Sir Ludwig would be interested to know that, as we sit here at this moment, the contracts are being finalised for a Tetraplegic Hostel in Perth for 40 beds, with a sheltered workshop, and it should be in operation by this time next year.

\section{ASCENDING CORD LESION IN THE EARLY STAGES FOLLOWING SPINAL INJURY}

\author{
By H. L. Frankel, M.B., M.R.C.P. \\ National Spinal Injuries Centre, Stoke Mandeville Hospital, \\ Aylesbury, Bucks., England

\section{INTRODUCTION}

IN the first weeks following spinal cord injury changes for the better or worse commonly occur, the most common improvements are complete lesions becoming incomplete and recovery in immediately inferior roots-the so-called 'root escape"; 